\title{
Açık Planlı Bürolarda, İşitsel Konforun Tasarım Parametresi Olarak Alınmasına Yönelik Bir Yaklaşım Örneği
}

\author{
An Example Approach for Taking of Auditory Comfort \\ as a Design Parameter in Open Planned Offices
}

Semran ÖZDEM GÜRTÜRK, ${ }^{1}$ 이 Neşe YÜĞRÜK AKDAĞ²

ÖZ

Hacimlerde, kullanıcıların eylemlerine uygun işitsel ortamın yaratılmasında, gürültünün denetlenmesi son derece önemlidir. Öte yandan, açık planlı büro, sanayi tesisi gibi kimi yapı tiplerinde hacimlerin fiziksel özellikleri ve işlevleri nedeniyle, gürültü daha da önemli bir sorun durumundadır. Açık planlı bürolar gerek ekonomik açıdan, gerekse yapım süresi açısından işletmeye olumlu katkılar sağlasa da, özellikle kullanıcılar için bir takım problemleri de beraberinde getirmektedir. Günümüze değin yapılan çalışmalar, pek çok açık planlı büroda, en önemli sorunun, gürültü olduğunu ortaya koymaktadır. Bu tür mekânlarda bölme duvarları bulunmadığı için, konuşmadan, telefonlardan ve diğer ofis araç gereçlerinden kaynaklanan sesler, ayak sesleri, klima ve aydınlatma düzeninin gürültüleri, ofis ekipmanı (faks makineleri, yazıcı gibi), dışarıdan gelen gürültüler çalışma verimini düşürmekte, kimi zaman da önemli sağlık problemlerine yol açabilmektedir. Bu durum, açık planlı büroların tasarımında, akustik önlemlerin bir tasarım parametresi olarak ele alınmasının gerekliliğini zorunlu kılmaktadır. Bu çalışmada, açık planlı büro örneği olarak, gürültü sorununun çok daha fazla olduğu bir çağrı merkezi incelemeye alınmıştır. Gözlem, anket ve ölçmeler gerçekleştirilmiş, ardından hacim modellenerek Soundplan 8.1 programına aktarılmıştır. Program yardımı ile öncelikle hacim içerisindeki mevcut gürültü düzey durumu ortaya konmuştur. Aynı programı aracılığı ile, hacim içerisinde personel sayısı, uygun çalışma ünitesi model tasarımları, bölücü eleman yükseklikleri, farklı yüzey yutuculukları değerlendirilerek en uygun akustik konfora sahip çağrı merkezi modeli ortaya konmaya çalışıımıştır. Bu çalışma ile işitsel ortamı iyileştirmek üzere alınması gereken önlemler, mimari ve akustik tasarım kapsamında belirlenerek, tasarımcılara yol gösterecek sonuçlar elde edilmiştir.

Anahtar sözcükler: Açık planlı ofis; akustik konfor; akustik tasarım parametreleri.

\section{ABSTRACT}

Noise audit is extremely important in creating an auditory environment suitable for the actions of users in volumes. On the other hand, due to the physical properties and functions of the volumes in certain buildings such as an open-plan office, industrial facility, noise is even a more important problem. Although open-plan offices make positive contributions to the business both in terms of costs and construction period, they also bring some problems especially for users. Studies to date reveal that the most important problem in many open-plan offices is noise. Since there are no partition walls in such places, sounds caused by speech, telephones and other office supplies, footsteps, air conditioning, and lighting noises, office equipment (i.e. (fax machines, printers), external noises reduce the efficiency of work and sometimes can lead to important health problems. As this clearly demonstrates, handling acoustic measures as a design parameter in the design of open-plan offices is a necessity. In this study, as an example of an open-plan office, a call center where the noise problem is very high was examined. Observations, surveys and measurements were carried out, then the volume was modeled and transferred to the Soundplan 8.1 program. The current noise level in the volume was first revealed by using the program. The call center model with the most appropriate acoustic comfort was sought to be determined in the same program by evaluating the number of personnel in the volume, suitable working unit model designs, divider element heights and different surface absorbents. The results of the current study regarding the measures to be taken to improve the audio environment within the scope of architectural and acoustic design may serve as a guide to the designers.

Keywords: Open plan office; acoustic comfort; acoustic design parameters.

'Fırat Üniversitesi Mimarlık Fakültesi, Mimarlık Bölümü, Elazığ

${ }^{2}$ Yıldız Teknik Üniversitesi Mimarlık Fakültesi, Mimarlık Bölümü, İstanbul

Başvuru tarihi: 03 February 2020 - Kabul tarihi: 04 May 2020

İletişim: Semran ÖZDEM GÜRTÜRK. e-posta: ozdemsemran@gmail.com

○ 2020 Yıldız Teknik Üniversitesi Mimarlık Fakültesi - @ 2020 Yıldız Technical University, Faculty of Architecture 


\section{Giriş}

Gelişen teknoloji, hızlı kentleşme, nüfus artışı, sanayinin gelişmesi, makineleşme gibi etkenler ile hem yapı içi hem de yapı dışı gürültü kaynakları çoğalmakta ve çeşitlenmektedir. Açık planlı ofisler de yapı içi gürültünün etkin olduğu mekânlardır. Gelişen teknoloji ile birlikte geleneksel bürolar, yerini açık planlı ofislere bırakmıştr. Açık planlı ofislerin, işletmeye sağladığı katkılar oldukça fazladır fakat bu hacimler fiziksel özellikleri ve işlevleri nedeniyle gürültünün önemli bir sorun olduğu mekânlardır. Gürültü açısından gereken denetim sağlandığında çalışma verimliliği yüksek açık planlı ofisler tasarlamak mümkündür. Literatürde bu konuyla ilgili yapılan çalışmalar aşağıda özetlenmiştir.

Açık planlı bürolarda çok sayıda çalışanın bir arada çaışmasının sonucu olarak, arka plan konuşmaları dikkat bozukluğuna neden olmaktadır. Uygun akustik tasarım yapılarak bu problem azaltılabilir. Yapılan bir çalışmada 16 farklı açık planlı büro incelenmiştir. Gürültü düzeyi ölçüm sonuçları dikkate alınarak açık planlı ofisler için akustik konforun sağlanması için çözüm önerileri geliştirilmiştir. ${ }^{1}$ Konuşma gizliliği parametresini göz önüne alan çalışmalarda ise, çalışma ünitelerindeki engel etkinliği artırılarak konuşma gizliliğinin sağlanması amaçlanmıştr. Çalışmalardan bir tanesinde, ISO 3328-3: 2012 standart ve hesaplama ilkelerine dayanılarak, ışın izleme simülasyonu yardımı ile büro tefrişi ve engel etkinliğinin yeniden düzenlenmesiyle akustik ortam iyileştirilmeye çalışılmıştır. Başka bir çalışmada, 15 çalışanın bulunduğu küçük bir açık planlı ofiste $44 \mathrm{dBA}$ düzeyinde yapay sesin maskeleme etkisi incelenmiştir. İnceleme sonucunda, çalışanların memnuniyetsiz olduğu ve arka plan gürültü düzeyinin çok yüksek olmadığı durumlarda maskelemenin uygun olduğu saptanmıştr. ${ }^{2}$ Açık planlı bir büro olarak tasarlanan laboratuvar ortamında gerçekleştirilen bir başka çalışmada, konuşmanın anlaşılabilirliğine yönelik koşullar incelenmiş ve sonuçta anlaşılabilirliğin düşük olması durumunda konuşmanın iletim indeksi (STI) $(S T K<0.35)$ çalışanların iş performansında önemli düşüşler gözlenmiştir. ${ }^{3}$ Bir diğer çalışmada, anlaşılamayan arka plan seslerini maskelemek için kullanılan pembe gürültü, enstrümantal müzik, vokal müzik ve su sesi gibi farklı sesler karşılaştrılmıştr. Sonuçta, su sesinin en uygun konuşma maskeleyicisi olduğu, bu nedenle enstrümantal ya da vokal müzik yerine açık planlı bürolarda durağan bir maskeleme sesi tercih edilmesi önerilmiştir. ${ }^{4}$ Bir proje kapsamında ise, beş adet açık planlı büroda akustik şartlar incelenmiş, bu kapsamda, yansışım süresi (T20), erken düşme süresi (EDT), clarity (C50), STI, konuşmanın anlaşılabilirlik indeksi (SII), gizlilik indeksi (PI) ve uzaklığın her iki katına çıktğındaki azalma oranı (DL2) parametreleri incelenmiştir. $\mathrm{Bu}$ parametrelerden elde edilen sonuçlar incelenmiş ve

\footnotetext{
Keränen \& Hongisto, 2013 s. 1315.

Hongisto, 2008, s. 1.
}

öneriler sunulmuştur. ${ }^{5}$ Açık planlı bürolarda arka plandaki doğal konuşma seslerinin iş performansı, kısa süreli sözlü hafiza performansı ve iş yüküne etkilerinin odeon simülasyon programı kullanılarak, farklı senaryo kurgularıyla analiz edildiği bir diğer çalışmada ise, doğal maskelemelerin yetersizliği, uygun tasarım ve maskeleme seslerinin uygulanması gerekliliği ortaya çıkmıştr. ${ }^{6}$ Açık planlı bir büronun akustik performansını değerlendirmek ve iyileştirmek için çözüm önerilerinin sunulmasının amaçlandığı çalışmada ise bilgisayar simülasyonu ve yerinde ölçüm yönteminden elde edilen veriler sonucunda, tavanın ses yutuculuğunu artırma ve çalışma birimleri arasındaki engellerin iyileştirilmesiyle birlikte bürodaki akustik şartların iyileştirildiği görülmüştür. ${ }^{7}$ Açık planlı bürolarla, özel bürolar arasındaki farkı ve akustik olarak bu farkın etkilerini belirlemeye yönelik çalışmalar da yapılmıştır. Çalışmalardan bir tanesinde, 31 çalışanın özel büro odalarından, açık planlı büroya taşınmasıyla işitsel ortamdaki değişim, taşınmadan önce ve sonra gerçekleştirilen anket çalışmalarıyla ortaya konmuştur. ${ }^{8}$ Konuya ilişkin bir diğer çalışmada, çalışanların geleneksel bürolardan açık planlı bürolara taşınmasının etkilerini incelemek için uzun süreli bir çalışma gerçekleştirilmiştir. Ölçüt olarak fiziksel çevre memnuniyeti, stres, iş ilişkileri, iş performansını etkileyen algılama vb. konular değerlendirilmiştir. Sonuç olarak tüm çalışanların memnuniyetinin azaldığı saptanmıştr. ${ }^{9}$ Açık planlı bir büroda ses kaynaklarının iş performansı ve algı üzerindeki etkilerinin incelendiği bir diğer çalışmada, yazıcı sesleri, anlaşılabilir konuşma, anlaşılmayan konuşma ve telefon sesleri gibi ses kaynaklarının çalışanların iş performansı üzerindeki etkisi değerlendirilmiştir. ${ }^{10}$

Literatür araştırması sonucunda, açık planlı ofislerdeki işitsel konfor koşullarına yönelik birçok çalışmanın gerçekleştirilmiş olduğu görülmektedir. Ancak, hem ses kaynağı, hem de alıcı durumunda olan çok sayıda çalışanın yer alması nedeni ile gürültü sorununun genelde çok fazla yaşandığı açık planlı ofis tiplerinden olan çağrı merkezleri için ayrıntlı bir çalışmaya rastlanmamıştı. Bu çalışma kapsamında, çağrı merkezlerinde, kullanıcı sayısı, engel tasarımı, iç yüzey gereçleri, yerleşim düzeni vb. birçok parametre değerlendirilerek, çağrı merkezi tasarım sürecinde uygun akustik konforun sağlanması için, tasarımcılara yol gösterici nitelikte sonuçların ortaya koyması amaçlanmıştır.

\section{Açık Planlı Ofislerde Akustik Konfor}

Açık planlı ofisler, çok sayıda çalışanın bir arada olduğu ve gürültünün kişileri genelde olumsuz etkilediği mekânlardandır. Açık planlı bürolarda, verimli ve kullanıcıların hoşnut olduğu çalışma ortamının sağlanmasında yer-

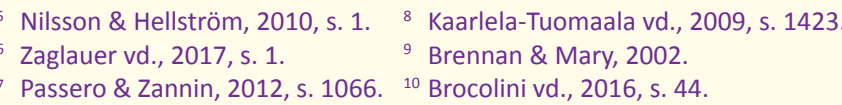


leşim düzeni, kişiler arasındaki iletişim, kişi başına düşen alan-hacim gibi özelliklerin yanı sıra başta gürültü olmak üzere, ısıtma-havalandırma, aydınlatma ve benzeri öteki fiziksel ortam öğeleri de önemli rol oynar. Konuya işitsel konfor açısından bakıldığında, bir açık planlı büronun akustik açıdan konforlu olabilmesi için yeterli konuşma gizliliğinin, anlaşılabilirliğinin ve gürültü düzeyinin kabul edilebilir düzeyin altında olmasının sağlanması gerekir. Bu gereksinimler ile ilgili önlemlerin tasarım sürecinde göz önüne alınması, kullanıcılara akustik konfor koşulları açısından uygun bir ortam oluşturulabilmesi için önemlidir. Bu çalışmada, akustiğin, açık planlı bürolarda tasarım parametresi olarak alınmasına yönelik, bir örnek kapsamında yapılan çalışmalara yer verilmiştir.

\section{Materyal ve Metod}

Çalışmada izlenen metot gösterildiği gibidir:

- Analizi yapılacak olan açık planlı ofisin özelliklerinin belirlenmesi

- Anket analizi ile büronun gürültü açısından durumunun belirlenmesi,

- Yerinde gürültü ölçümleri yapılarak hacimdeki gürültü düzeyinin belirlenmesi ve açık planlı ofisin mevcut durumunun simülasyon programı aracılığıyla gürültü haritasının çıkarılması,

- Tasarım modeli oluşturmak için, yerleşim önerileri, toplam yutuculuk ve engel etkinliğinin değerlendirilmesi.

\section{Örnek Açık Planlı Ofisin Özellikleri}

Açık planlı ofis yapılarından çağrı merkezlerinde yaşanan akustik sorunları incelemek ve getirilebilecek önlemleri belirleyerek, uygun tasarım modeli hazırlamak amacıyla, Türkiye'de yer alan, yaklaşık 600 çalışanın bulunduğu çağrı merkezine ait bir açık planlı büro incelemeye alınmıştır. Çağrı merkezi iş istihdamı açısından, şehir için önemli bir çalışma alanıdır. Yapı çevresel gürültü açısından yoğunluğu az bir karayolu trafiğine maruz kalmaktadır. Çağrı merkezi bodrum+zemin+üç kattan oluşmaktadır. Her kat farklı sayıda çalışanın bulunduğu açık planlı ofis olarak kullanılmaktadır. Yapının, ikinci katında yer alan 220 kişilik çalışma alanı bulunan çağrı merkezi, inceleme ve değerlendirmeler için seçilmiştir. Şekil 1'de hacmin genel görünüşü, Şekil 2'de ise hacmin bilgisayarda hazırlanan üç boyutlu modeli yer almaktadır. Hacmin genel özellikleri aşağıda görüldüğü gibidir:

- Yapı kabuğu, çift cam ve gaz betondan oluşmaktadır. Cam yüzeyler, perde, jaluzi benzeri öğeler kullanılmadığı için, hacim için yansıtıcı yüzey durumundadır. Duvarlarda uygulanan su bazlı boya da, sesi büyük oranda yansıtmaktadır.

- Döşemelerde ses yutuculuğu oldukça yüksek olan halı kullanılmıştır.

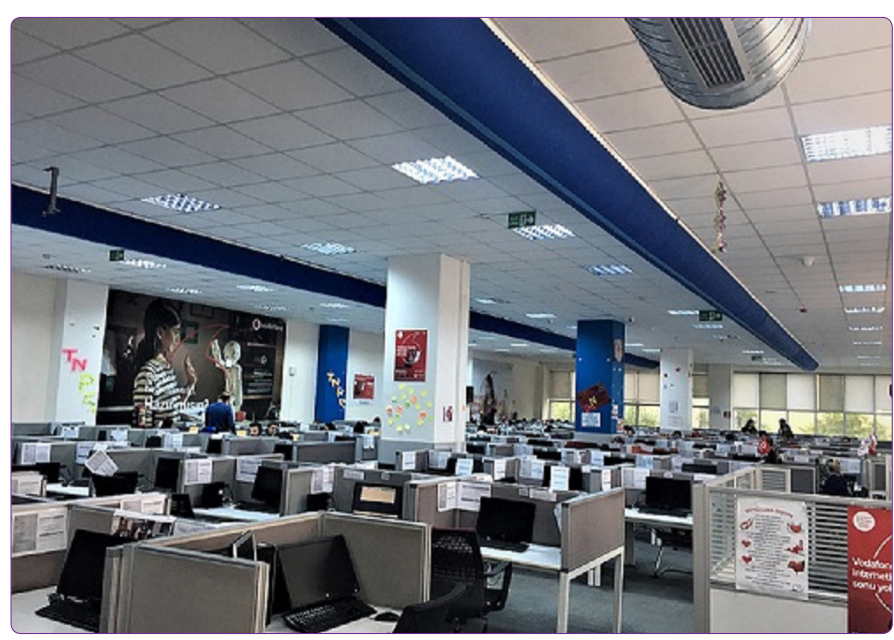

Şekil 1. Hacmin genel görünüşü.

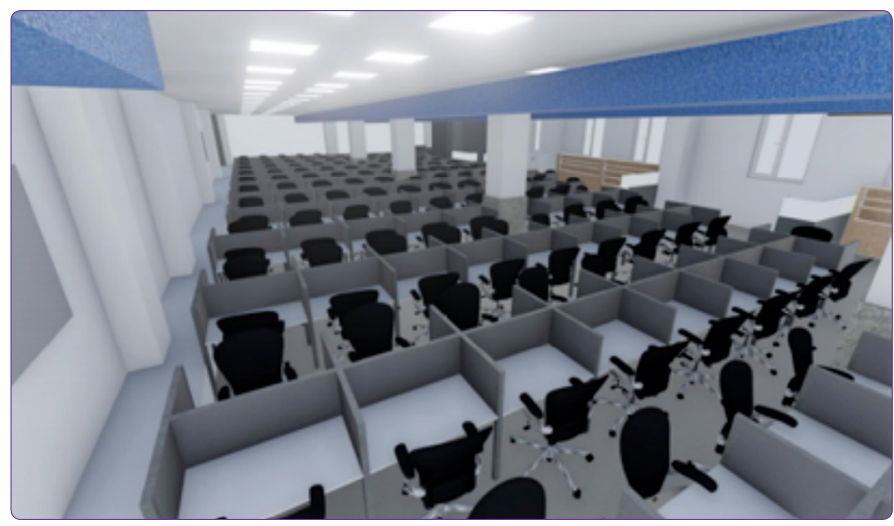

Şekil 2. Çağrı merkezi mevcut durum üç boyutlu modelleme.

- Asma tavan taş yünü levhalardan oluşmaktadır. Tavandan geçen havalandırma kanalları kumaş malzeme ile kaplanmıştır (Şekil 1).

- Çalışanlar arasında $50 \mathrm{~cm}$ yüksekliğinde, kumaş kaplı bölücü elemanlar bulunmaktadır.

- Çalışma saatleri sabah 09.00-akşam 19.00 olan hacimde 156 kişi çalışmaktadır.

- Çağrı merkezinde etken gürültü kaynakları; konuşma, telefon sinyal sesi ve büro araç gereçlerinin sesleridir. Yapı dışında ise önemli bir gürültü kaynağı bulunmamaktadır.

\section{Çağrı Merkezi Anket Analizi}

Yapılan araştırmalara göre açık planlı bir ofiste, çalışma mekânından kaynaklı işten ayrılma nedenlerinin çoğunu gürültü oluşturmaktadır. Çalışma kapsamında çağrı merkezi çalışanlarının öznel değerlendirmelerini belirleyebilmek amacı ile anket çalışması yapılmıştır. Anket soruları yüz kişiye yöneltilmiş ve 88 çalışandan geri bildirim alınabilmiştir. Bu çalışma ile çağrı merkezinde bulunan çalışanların cinsiyet dağılımı, yaş ortalaması, eğitim durumu, yaşanan akustik ve fiziksel konfor şartları ve bu şartların çalışanlar üzerindeki fiziksel ve psikolojik etkileri belirlen- 
Tablo 1. Anket sonuçları

Katılımcıların cinsiyeti

Katııımcıların yaş aralığı ve yaş aralığına göre gürültüden etkilenme oranları

Akustik ve fiziki konfor koşulları rahatsızlık profili

Rahatsız olunan gürültü etkenleri

Oluşan fiziksel sağlık problemleri

Oluşan psikolojik sağlık problemleri

Konuşma gizliliği durum değerlendirme

Arka plan seslerinin iş performansı üzerinde etkisi

\section{Kadın \%59}

Erkek \%41

18-25 yaş \%28-\%80 gürültülü \%16 kısmen gürültülü 25-30 yaş \%43-\%76 gürültülü \%24 kısmen gürültülü 30-35 yaş \%19-\%50 gürültülü \%45 kısmen gürültülü 35-40 yaş \%7-\%42 gürültülü \%36 kısmen gürültülü $\% 47$ kötü ya da çok kötü $\% 40$ orta

$\% 13$ iyi

$\% 94$ konuşma sesleri

$\% 33$ donanım sesleri

$\% 32$ tesisat sesleri

$\% 30$ ayak sesleri

$\% 85$ baş ağrısı

\%29 işitme bozukluğu

$\% 28$ uyku problemi

$\% 66$ stres

$\% 48$ sinirlilik

\%45 algılamada güçlük

\%43 konuşma gizliliği yoktur

\%27 konuşma gizliliği kısmen vardır

$\% 29,5$ konuşma gizliliği vardır

$\% 50$ olumsuz etkiliyor

$\% 32$ kısmen olumsuz etkiliyor

$\% 13$ olumsuz etkilemiyor meye çalışılmıştır. Anket sonuçları, Tablo 1'de yer almaktadır.

Anket çalışması, açık planlı büro yapılarında gürültünün çalışanların çalışma verimliliğini düşüren ve sağlığını bozan en önemli etkenlerden biri olduğunu ortaya koymuştur. Özellikle konuşma sesleri, hacim içerisinde akustik konforsuzluğa neden olan en önemli etkendir. Anket sonuçları göz önünde bulundurulduğunda çalışma kapsamında, değerlendirilen hacmin akustik açıdan iyileştirilmesi gerekliliği görülmektedir.

\section{Çağrı Merkezi Gürültü Düzeyi Ölçmeleri}

Çağrı merkezinin işitsel konfor durumunu belirlemek amacıyla gürültü düzeyi ölçümleri gerçekleştirilmiştir. Ölçmeler, Sound level meters Nor 131ölçüm cihazı kullanılarak, Şekil 3'te belirtilen 12 noktada gerçekleştirilmiştir. TS ISO 1996-2'ye ${ }^{11}$ uygun olarak gerçekleştirilen ölçmeler, etkin gürültü kaynağının ve alıcıların oturan kişiler olması nedeni ile zeminden 1.10 m yükseklikte gerçekleştirilmiştir. Ölçmeler, 5 Mart 2019 tarihinde 15.00-17.30 saatleri arasında ve her bir noktada 10'ar dakika olarak gerçekleştirilmiştir. Eşdeğer sürekli gürültü düzey değerlerinin (LAeq)

\footnotetext{
${ }^{11}$ TS ISO 1996-2, 2009
}

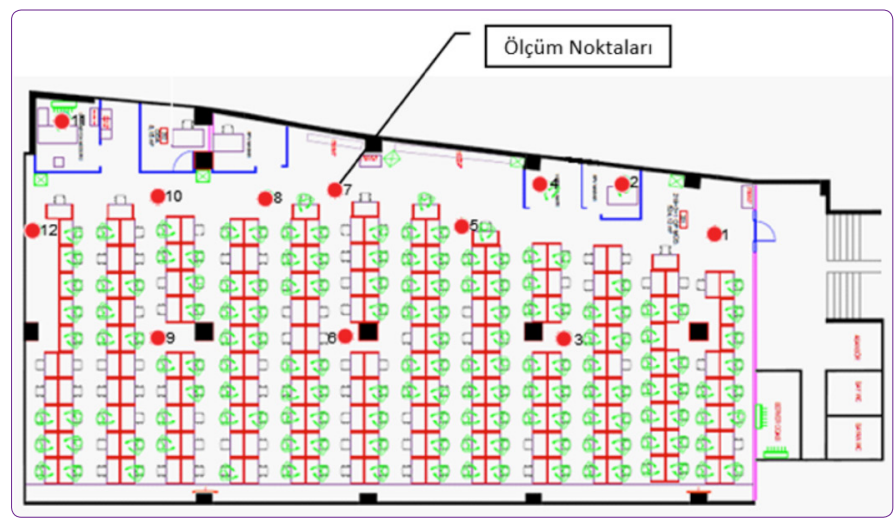

Şekil 3. Açık planlı ofis kat planı, ölçüm yapılan noktalar.

yanı sıra, farklı oktav aralıklarında frekans analizi de yapılmıştır.

Açık planlı bürolarda kabul edilebilir düzeyler ve ölçüm sonuçları Tablo 2'de yer almaktadır. Türkiye'de yürürlükte olan "Binaların Gürültüye Karşı Korunması Hakkındaki Yönetmelik", açık planlı bürolar için kabul edilebilir gürültü düzeyini, büro yeni yapılacak ( $C$ sınıfi) ise, $44 \mathrm{~L}_{\text {Aeq }}$ mevcut (D sınıfi) ise $48 \mathrm{~L}_{\text {Aeq }}$ olarak vermektedir. ${ }^{12}$ Kabul edilebilir

\footnotetext{
${ }^{12}$ Çevre ve Şehircilik Bakanlığı, 2018.
} 
Tablo 2. Ölçüm noktaları gürültü düzeyleri ve ofislerde kabul edilebilir gürültü düzeyleri

\begin{tabular}{|c|c|c|c|c|c|c|c|}
\hline Ölçüm noktaları & LAeq & $125 \mathrm{~Hz}$ & $250 \mathrm{~Hz}$ & $500 \mathrm{~Hz}$ & $1000 \mathrm{~Hz}$ & $2000 \mathrm{~Hz}$ & $4000 \mathrm{~Hz}$ \\
\hline 1 & 63 & 55.7 & 51.1 & 56.8 & 53.7 & 48.2 & 43.9 \\
\hline 2 & 61.6 & 58.2 & 50.1 & 55.3 & 52.1 & 46.7 & 41.1 \\
\hline 3 & 63.3 & 53.3 & 52.7 & 58.2 & 53.1 & 47.9 & 42.7 \\
\hline 4 & 61.7 & 54.6 & 49.5 & 55.8 & 51.9 & 46.8 & 40.4 \\
\hline 5 & 64.2 & 48.9 & 53.2 & 59.1 & 54.1 & 48.2 & 43.1 \\
\hline 6 & 62.0 & 51.0 & 51.0 & 56.2 & 52.3 & 46.6 & 40.8 \\
\hline 7 & 64.9 & 49.3 & 55.9 & 59.1 & 56.2 & 49.5 & 43.6 \\
\hline 8 & 62.3 & 52.3 & 51.0 & 56.2 & 52.9 & 47.3 & 41.5 \\
\hline 9 & 61.3 & 48.4 & 50.6 & 55.7 & 51.8 & 46.1 & 40.6 \\
\hline 10 & 60.4 & 47.5 & 49.7 & 54.7 & 50.4 & 45.3 & 40.6 \\
\hline 11 & 59.4 & 43.2 & 49.4 & 53.7 & 49.7 & 44.4 & 38.4 \\
\hline 12 & 60.5 & 42.0 & 52.4 & 52.4 & 51.0 & 48.7 & 42.1 \\
\hline Ortalama & 62 & 56 & 51 & 56 & 52 & 47 & 42 \\
\hline Kabul edil. Gür. Düz. (NCB 45) & 48 & 58 & 53 & 50 & 47 & 43 & 40 \\
\hline
\end{tabular}

gürültü düzeyinin frekanslara göre değerlendirilmesine olanak tanıyan NCB (Balanced Noise Criteria) ölçütlerinin, genel bürolar için kabul edilebilir değeri NCB45 olarak verilmektedir. ${ }^{13}$

Tablo 2'de yer alan ölçüm sonuçları değerlendirildiğinde hacim içerisindeki ses düzeyinin toplam düzey ve frekans fonksiyonunda, açık planlı bürolar için kabul edilebilir gürültü düzeyinin üzerinde olduğu görülmektedir. Sadece 125 $\mathrm{Hz}$ ve $250 \mathrm{~Hz}$ frekanslarında kabul edilebilir değerin altında değerlere ulaşılmıştir. Bunun temel nedeni, hacmin oldukça büyük olmasına karşın, ses yutucu gereçlerin yeteri kadar kullanılmaması ve hacimde çok sayıda kaynak durumunda olan konuşmacının bulunmasıdır. İç yüzey gereçlerinden belli oranda ses yutucu özellikli olarak, döşemede halı, tavanda taş yünü asma tavan ve ara bölme elemanı olarak kumaş kaplı engel panelleri kullanılmıştr. Fakat oldukça geniş yüzeyler oluşturan pencere camları, aydınlatma amaçlı kullanılan armatürler ve duvarlarda kullanılan sıva ses yutuculuğu açısından zayıftır. Gürültü düzeyinin bu denli yüksek olmasının bir başka nedeni, $570 \mathrm{~m}^{2}$ olan alanda, 156 kişinin çalışmasıdır. Bu durumda kişi başına $3.6 \mathrm{~m}^{2}$ alan düşmektedir. Oysa açık planlı ofislerde sirkülasyonu uygun olan bir çalışma alanı için genel olarak bir personele $6 \mathrm{~m}^{2}-9 \mathrm{~m}^{2}$ arasında değişen boyutlarda alanlar tahsis edilmelidir. ${ }^{14}$

Hacim içerisinde çok fazla çalışanın bulunması gürültü düzeyinin kabul edilebilir değer aralıklarının üzerinde çıkmasındaki en önemli etkenlerden biridir. Hacimde olması gereken çalışan sayısı yaklaşık 80 kişiliktir. Şekil 4'te ise, hacimdeki ortalama gürültü düzeyi (değişik noktalarda ölçülen düzeylerin ortalaması) kabul edilebilir eğrilerle birlikte değerler karşılaştırılmıştır.

\footnotetext{
${ }^{13}$ Maekawa \& Lord, 1994, p. $377 .{ }^{14}$ Haapakangas vd., 2014, s. 1.
}

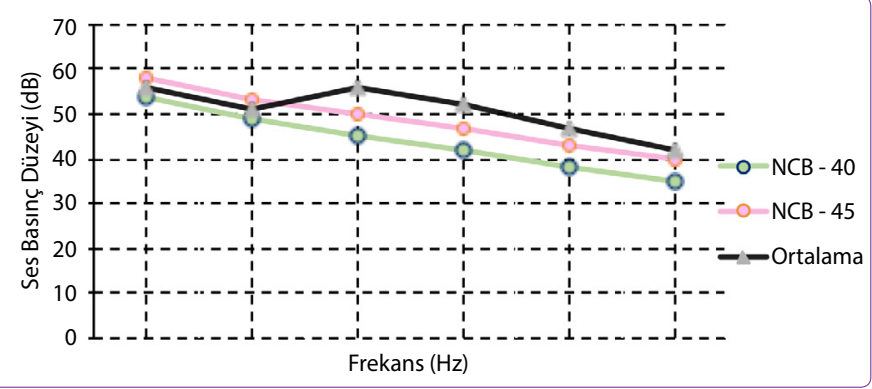

Şekil 4. Hacmin ortalama gürültü düzeyinin NCB 40-45 eğrileri ile karşılaştırılması.

Şekil 4'te tüm noktalarda ölçülen değerlerin ortalaması verilmiştir. NCB 40 ve NCB 45 eğrileri ile ortalama değer kıyaslandığında $500 \mathrm{~Hz}, 1000 \mathrm{~Hz}$ ve $2000 \mathrm{~Hz}$ frekanslarında ses basınç düzeyi kabul edilebilir değerlerin üzerindedir. Hacim içerisinde bulunan 156 çalışan sayısı ve her birinin sürekli çağrı alması çalışanların hem kaynak hem alıcı nitelikte değerlendirilmesi sonucunu doğurmuştur. Yapılan anket çalışması ve gürültü düzey ölçümleri sonucunda inceleme yapılan açık planlı ofiste gürültünün çalışma verimliliğini düşüren, psikolojik ve fizyolojik sağlık problemine yol açan bir etken olduğu ortaya çıkmıştır.

\section{Çağrı Merkezi Mevcut Durumunun Bilgisayar Programında Değerlendirilmesi}

Çağrı merkezindeki gürültü problemini daha ayrıntılı ortaya koymak ve alınabilecek önlemleri belirlemek üzere soundPLAN 8.1 simülasyon programı kullanılarak hacmin gürültü haritası hazırlanmıştır. Gürültü haritası hazırlanırken aşağıdaki adımlar izlenmiştir:

- Hacim mobilyaları, iç yüzey gereçleri ve kişilerin ses yutma çarpanları programın kitaplığından seçilerek 
Tablo 3. Açık planlı büro içerisinde kullanılan malzemeler

\begin{tabular}{|c|c|c|c|c|c|c|c|}
\hline \multirow[t]{2}{*}{ Gereçler } & & \multicolumn{6}{|c|}{ Ses yutma çarpanı (a) } \\
\hline & & $125 \mathrm{~Hz}$ & $250 \mathrm{~Hz}$ & $500 \mathrm{~Hz}$ & $1 \mathrm{kHz}$ & $2 \mathrm{kHz}$ & $4 \mathrm{kHz}$ \\
\hline Döşeme & Halı kaplama & 0.050 & 0.1 & 0.150 & 0.3 & 0.5 & 0.550 \\
\hline Tavan & Taş yünü asma tavan & 0.53 & 0.95 & 0.97 & 0.97 & 0.97 & 0.98 \\
\hline Duvar & Beton üzeri pürüzsüz sıva & 0.01 & 0.01 & 0.02 & 0.02 & 0.02 & 0.04 \\
\hline Duvar kaplama & Ahşap panel & 0.08 & 0.08 & 0.09 & 0.09 & 0.1 & 0.12 \\
\hline Pencere & Lamine cam & 0.28 & 0.20 & 0.110 & 0.060 & 0.030 & 0.020 \\
\hline Engel & Kumaş kaplı panel & 0.1 & 0.3 & 0.35 & 0.45 & 0.5 & 0.4 \\
\hline
\end{tabular}

tanımlanmıştır. Illgili yutma çarpanları Tablo 3'te yer almaktadır.

- Hacimde gürültü kaynağı durumunda olan, çalışan kişiler için ses gücü düzeyi, programın kitaplığından seçilerek, 64 dBA olarak tanımlanmıştr.

- Belli zaman aralığı için LAeq hesabı yapıldığı için, büronun çalışma saatleri olarak, 09.00 -19.00 saat aralığı programa tanımlanmıştır.

- TS ISO 1996-2'ye göre yapılan ölçüm kriterleri, gürültü haritası oluşturulurken de gözönünde bulundurulmuştur.

- Çevresel gürültünün değerlendirilmesi ve yönetimi yönetmeliğine göre hesaplamalarda ızgara alanı 10 m, yerden yükseklik 1.1 m olarak alınmıştır. Harita, 2 dBA aralıklarla renklendirilmiştir.

- Çağrı merkezleri için önerilen yansışım süresi değerleri ile karşılaştırma yapmak üzere, hacmin yansışım süresi hesabı da gerçekleştirilmiştir.

Şekil 5'te mevcut durum gürültü haritası değerlendiğinde, gürültünün hacim genelinde 61-67 $\mathrm{L}_{\text {Aeq }}$ arasında değiştiği görülmektedir. Simülasyon sonucunda da, hacmin gürültü düzeyinin kabul edilebilir değer aralıklarının 20 dBA kadar üzerinde olduğu görülmektedir.

Çağrı merkezlerinde, yansışım süresinin 0.1 ile 0.4 saniye aralığında olması önerilmektedir. ${ }^{15}$ Öte yandan, gerçekleştirilen hesaplar sonucunda hacmin ortalama yansışım süresinin $0.59 \mathrm{~s}$ olarak, olması gereken aralığın üzerinde bir değerde olduğu belirlenmiştir.

\section{Simülasyonun Doğrulanması}

Gürültü düzeyi ölçüm sonuçları ile, simülasyon sonuçlarının daha ayrıntılı karşılaştırmasını yapabilmek amacı ile, gürültü düzeyi ölçümlerinin gerçekleştirildiği 12 alıcı noktası için, soundPLAN 8.1 programında, tek nokta gürültü düzeyi hesapları da yapılmıştır. Ölçüm ve simülasyondan elde edilen sonuçlar Şekil 6'da yer almaktadır.

\footnotetext{
${ }^{15}$ Acustic Bulletin, 2006.
}

Şekil 6'da P(1-12) ölçüm noktalarını göstermektedir. Deneysel ölçümler ile simülasyon programından elde edilen değerler birbirine çok yakındır. Örneğin P3 noktasında ölçülen değer $63.3 \mathrm{dBA}$ iken simülasyonda bu değer $63 \mathrm{dBA}$ 'dır.

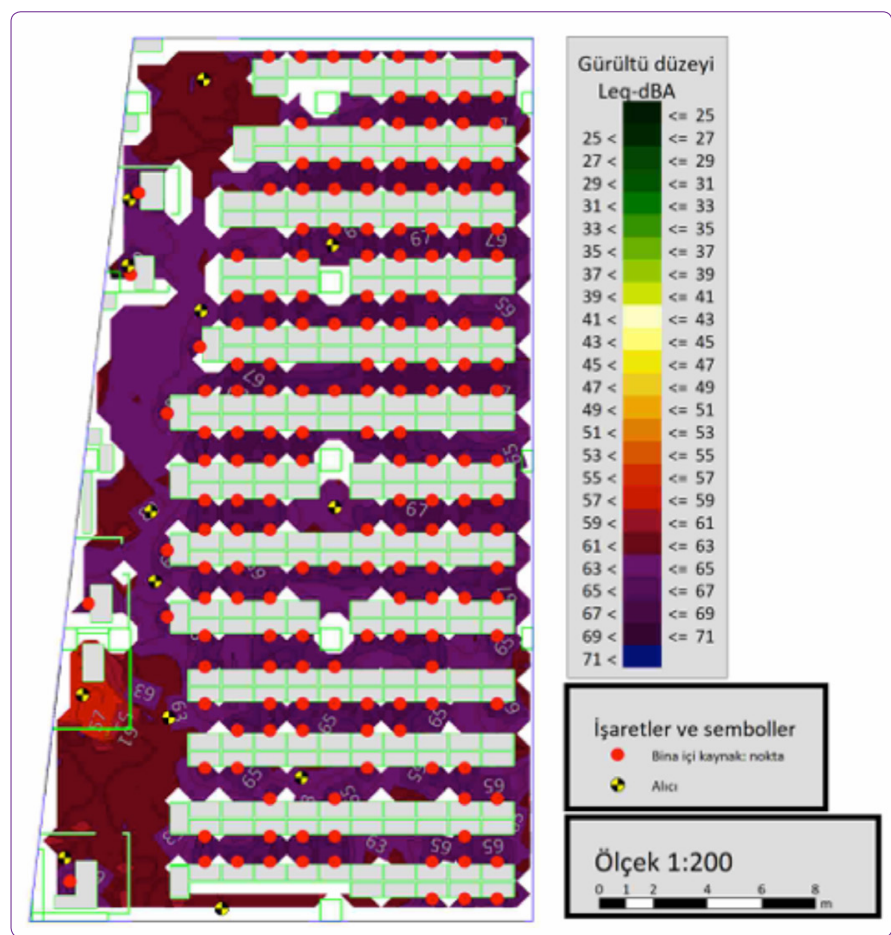

Şekil 5. Çağrı merkezi mevcut durumu gürültü düzey dağııımı.

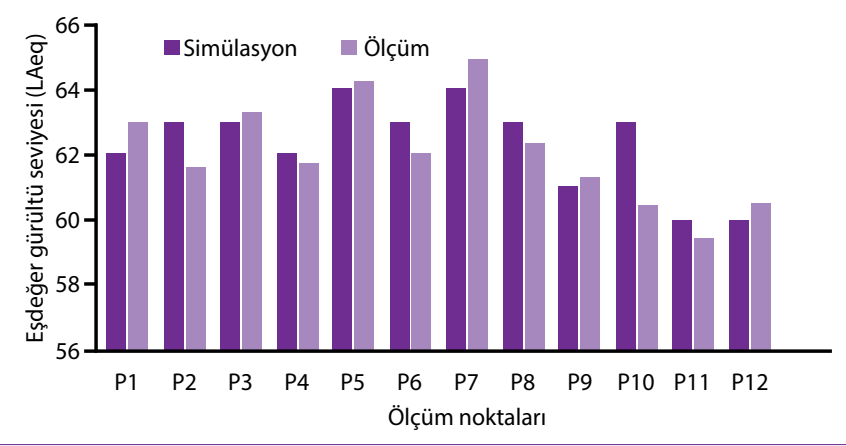

Şekil 6. Ölçüm ve simülasyon çalışmalarından elde edilen ses düzey değerlerinin karşılaştırılması. 


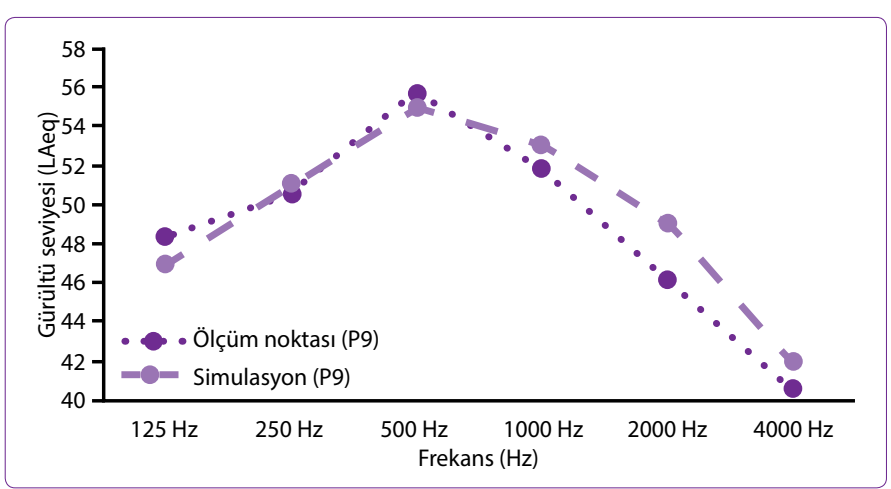

Şekil 7. Ölçüm ve simülasyon çalışmalarından elde edilen değerlerin karşılaştırılması.

Sadece P10 noktasında deneysel ve simülasyon çalışmasından elde edilen değerler arasında $3 \mathrm{dBA}^{\prime}$ lık fark vardır. Bunun nedeni, ses düzey ölçümü gerçekleştirilirken ölçüm cihazının bulunduğu bazı noktalarda, sirkülasyon yoğunluğunun sürekli olarak devam etmesidir. Ayrıca hangi frekans aralığında gürültü düzeyinin yüksek olduğunu tespit etmek için, $125 \mathrm{~Hz}$ ve $4000 \mathrm{~Hz}$ arasında oktav aralıklarla frekans analizi yapılmıştı. Sirkülasyon alanının yoğun olmadığı P9 noktası referans alınarak, frekans analizi yapılmıştı. Ölçme ve simülasyondan elde edilen sonuçlar (P9 için) Şekil 7'de karşılaştrılmıştır.

Şekil 7'de gösterildiği gibi ses düzey ölçümü ve simülasyon programında elde edilen değerler birbirine çok yakındır. Bu veriler simülasyon çalışmasının doğruluğunu göstermektedir.

\section{Bulgular}

Hacim özellikleri belirlenen çağrı merkezinde, anket çaIışmaları, gürültü düzey ölçümleri ve simülasyon programı aracılığıyla akustik konfor durumunun istenilen nitelikte olmadığı ortaya çıkmış ve gürültünün çalışanlar üzerinde psikolojik ve fizyolojik sağlık problemlerine neden olduğu, iş verimini düşürdüğü sonucuna varılmıştır. Hacim içerisinde yapılan çalışmalarda konuşma seslerinin en önemli gürültü etkeni olduğu saptanmıştır. Gürültü haritası değerlendirildiğinde, renk skalasına göre ofis içerisinde gürültü düzeyinin genel olarak 60 dBA'nın üzerinde olduğu görülmüştür. Çalışan sayısının hacme oranla fazla olması, kullanılan çalışma ünitelerinin uygun tasarlanmaması ve hacimde iç yüzeylerindeki ses yansıtıcı yüzeylerin, akustik konforsuzluğa neden olan etkenler olduğu belirlenmiştir.

\section{Çağrı Merkezinde Akustik Konforun İyileştirilmesine Yönelik Çalışmalar}

Büro hacminde anket analizi ve yapılan ölçüm sonuçlarının değerlendirilmesi ile belirlenen olumsuz akustik ortamı iyileştirmeye yönelik çalışmalar aşağıda yer alan adımlarla ele alınmıştır;
- Personel sayısının azaltılması,

- Farklı çalışma ünite modelleri,

- Toplam ses yutuculuğunun arttrılması, ara bölme elemanlarının etkinliğinin artırılması.

\section{Personel Sayısının Azaltılması}

Çağrı merkezinin hacmi $2687 \mathrm{~m}^{3}$ ve toplam alanı 540 $\mathrm{m}^{2 \prime}$ dir. Literatürde, açık planlı ofisler için kişi başına $6 \mathrm{~m}^{2}$ ile $9 \mathrm{~m}^{2}$ aralığında değişen bir çalışma alanı yeterliyken, $6 \mathrm{~m}^{2 \prime}$ nin altındaki değerlerin konforsuz hacimler olduğu kabul edilmektedir. ${ }^{16}$ Değerlendirmeye alınan çağrı merkezinde, çalışan başına düşen alan sadece $2.5 \mathrm{~m}^{2 \prime}$ dir. Açık planlı ofisler için önerilen tavan yüksekliği 2.5 ile $4 \mathrm{~m}$ arasında değişmektedir. Hacimde tavan yüksekliği 5 m'dir, fakat çalışan sayısının fazla olması kişi başına düşen hacmin de önerilen edilen değerden daha düşük olmasına neden olmaktadır.

Alanda çalışan sayısındaki azalma çağrı merkezindeki akustik konforu sağlamadaki en önemli parametredir. Personel sayısındaki azalma aynı zamanda gürültü kaynaklarının da azalmasını sağlayacaktır. Bu bağlamda hacim içerinde akustik konforu sağlamak amacıyla kişi başına düşen yeterli alanı sağlamak amacıyla, hacimdeki personel sayısı 80 kişiye düşürülmüştür. Bu durumda çağrı merkezinde çaIışanlara düşen alan kişi başına $7.1 \mathrm{~m}^{2}$ olmuştur.

\section{Farklı Çalışma Ünite Model Önerileri}

Çağrı merkezinde çalışan personel sayısı yarıya indirilerek oluşturulan çalışma alanında farklı çalışma üniteleri uygulanarak akustik konfor şartlarını optimum düzeye getirebilmek için en uygun çalışma alanı belirlenmeye çalışılmıştır. Şekil 8'de gösterildiği gibi çalışan sayısı yarıya düşürülerek 5 farklı çalışma ünitesi modeli oluşturulmuştur. Model 1'de çalışanlar arasındaki mesafe artırılmış, en yakın iki çalışan arasındaki direk sesin ulaşımının engellenmesi ise engel panelleriyle sağlanmıştır. Model 2'de kübik çalışma alanına sahip, çalışanların karşılıklı konumlandırıldığı, birbirine direk sesin ulaşımının aradaki panellerle engellenmeye çalışıldığı, kübik bir çalışma grubu oluşturulmuştur. Model 3'te ise üniteler kübik çalışma alanında köşe noktalara konumlandırılmıştır ve aralarında engel panelleri mevcuttur. Model 4'te kübik çalışma alanları iki gruba ayrılmış, çalışanlar aynı yönde yerleştirilmiş, çalışma alanları direk sesin geçişini engelleyecek şekilde yerleştirilmiştir. Model 5 ise Model 4 gibi konumlandırılmış fakat çalışanlar zIt yönde yerleştirilmiştir.

Çalışma kapsamında, beş farklı çalışma ünitesi yerleşiminde çalışanların, akustik konfor durumunun belirlenmesi amacıyla SoundPLAN 8.1 simülasyon programı ile beş farklı durumun gürültü haritası hazırlanmıştr. Toplam yutuculuk

\footnotetext{
${ }^{16}$ Quentin, 2002.
} 


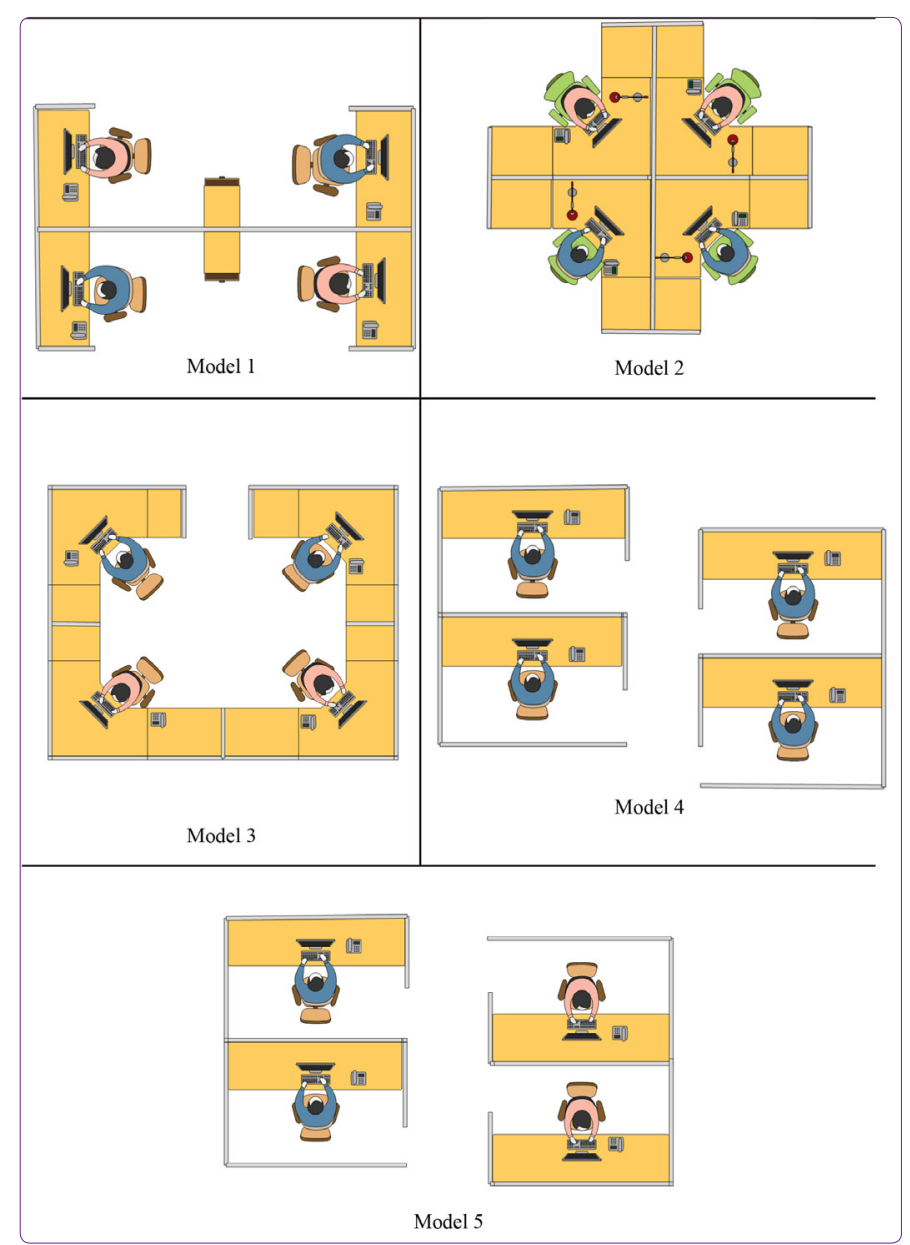

Şekil 8. Çağrı merkezine yerleştirilen farklı çalışma ünitesi modelleri.

ve engel etkinliği sabit tutularak personel sayısı ve çalışma ünitesi etkinliği ile açık planlı ofisler için kabul edilebilir değere en uygun model belirlenmeye çalışılmıştır (Şekil 9-11).

- Model 1'deki çalışma ünitesi yerleşimi simülasyon programı aracılığı ile değerlendirildiğinde, Şekil 9'da görüldüğü gibi hacim içinde gürültü düzeyi $55 \mathrm{dBA}$ ile $63 \mathrm{dBA}$ aralığında değişmektedir. Bu yerleşim ile mevcut durum yerleşim gürültü haritaları karşılaştırıldığında gürültü düzeyinde $4 \mathrm{dBA}$ dolaylarında azalma sağlanmıştır. Bu yerleşim modelinde yansışım süresi 0.51 sn'dir. Çağrı merkezlerinde istenen yansışım süresi değer aralığının üstünde bir değer çıkmıştır.

- Model 2'de görüldüğü gibi, kübik çalışma alanında çalışanlar yüz yüze oturmuş fakat engel panelleri ile direk sesin ulaşımı engellenmiştir. Hacimde toplam yutuculuk ve engel yüksekliği yine sabit tutulmuştur. Hacim içerisindeki gürültü düzey dağıımı $55 \mathrm{dBA}$ ile $61 \mathrm{dBA}$ aralığında değiştiği görülmektedir. Bu koşullarda, ses düzeyinde, mevcut duruma göre $6 \mathrm{dBA}$ kadar azalma görülmektedir. Bu yerleşim modelinde de yansışım süresi 0,5 sn'dir. Çağrı merkezlerinde istenen yansışım süresi değer aralığının üstünde bir değer çıkmıştır.

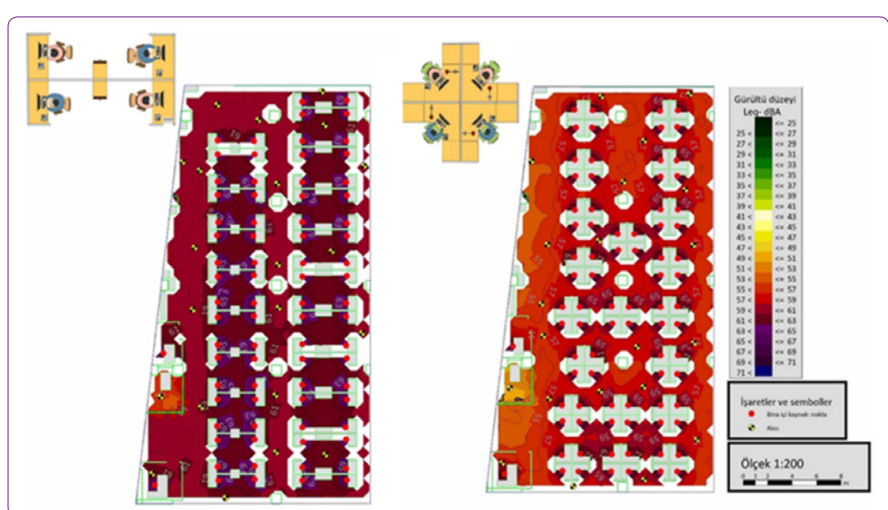

Şekil 9. Çağrı merkezi Model 1 (sol) ve Model 2(sağ) gürültü düzey dağılımı gürültü haritası.

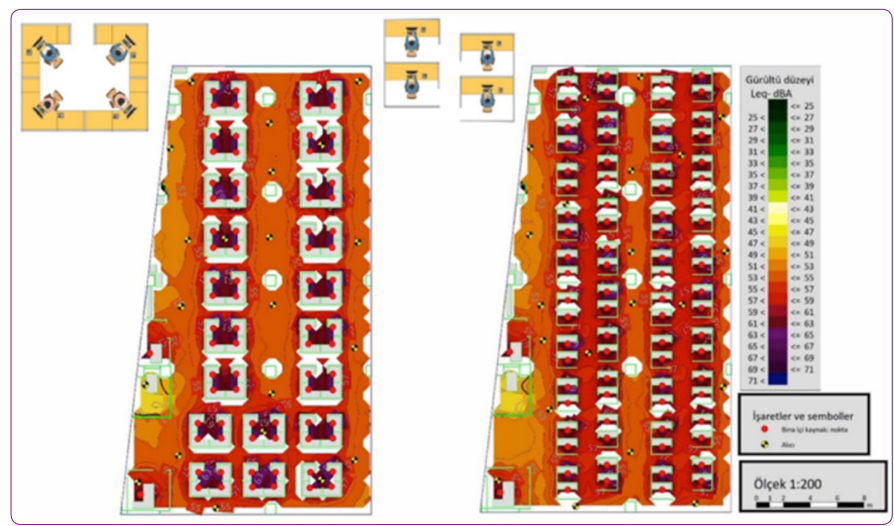

Şekil 10. Çağrı merkezi Model 3(sol) ve Model 4(sağ) gürültü düzey dağılımı gürültü haritası.

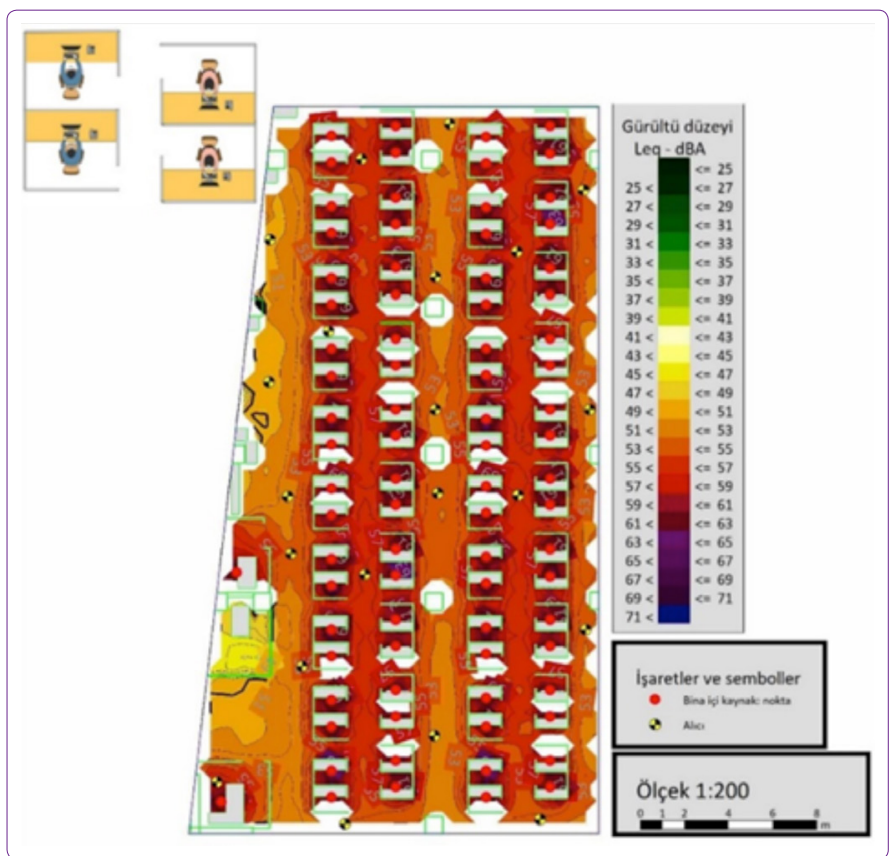

Şekil 11. Çağrı merkezi Model 5 gürültü düzey dağılımı gürültü haritası.

- Model 3'te çalışma birimleri, en yakın iki çalışana ait sesin birbirine ulaşmasını engelleyecek şekilde ko- 
numlandırılmıştır. Toplam yutuculuk ve engel yüksekliği sabittir. Çalışanların yüzü yutucu yüzeylerden oluşan engel panellerine dönüktür. Burada, sesin, hacme dağılmadan yutulması amaçlanmıştır. Sirkülasyon alanlarında ses düzeyi 53-55 dBA aralıklarında değişmesine rağmen, çalışma birimlerinde yerleşimden dolayı kırınan sesler çalışma ünitesi içerisinde gürültü düzeyinin artmasına neden olmuştur. Çalışma birimlerinde gürültü düzeyi 57 dBA- $59 \mathrm{dBA}$ aralığındadır. Bu yerleşim modelinde yansışım süresi 0.5 sn'dir. İstenen değer aralığının üstünde bir değerdir.

- Model 4 ve Model 5'te çalışanların girişleri birbirinden olabildiğince uzak ve engel panelleriyle çevrilerek optimum düzeyde sönümlenme sağlayacak şekilde yerleştirilmiştir. Model 4'te çalışanlar aynı yönde konumlandırılmış, Model 5'te ise çalışanlar zıt yönde konumlandırılmıştır. Model 4'teki gürültü haritasında gürültü düzey dağılımı incelendiğinde alıcı noktalardaki gürültü seviyesinin genel olarak $55 \mathrm{dBA}$ civarında çalışma alanlarında ise $57 \mathrm{dBA}$ civarında olduğu görülmüştür. Yansışım süresi 0.5 sn'dir.

- Karşııkı çalışanların zıt yönde yerleştirildiği Model 5 'te ise gürültü haritasına göre ses düzeyinde daha fazla azalma görülmüştür. Şekil 11 'de sirkülasyon alanlarındaki gürültü düzeyi $53 \mathrm{dBA}$ civarındayken çalışma alanlarındaki gürültü düzeyi $55 \mathrm{dBA}$ civarındadır. Örnek konumlandırılmalara göre en uygun çalışma alanı, farklı girişlerden oluşan Şekil 11'deki kübik yerleşim birimidir. Çalışan sayısı yarıya düşürülüp, mevcut yutuculuk ve engel yüksekliği kullanılarak Model 5'e göre yerleştirilen çalışma üniteleri ile hacim içerisinde $10 \mathrm{dBA}$ kadar gürültü düzeyinde azalma sağlanmıştır. Fakat elde edilen değerler (53$55 \mathrm{dBA}$ aralığı), açık planlı ofisler için kabul edilebilir değer olan 44 LAeq'nun üzerindedir. Kabul edilebilir değerlere en yakın ses düzeyine sahip olan Model 5 üzerinde, simülasyon programı aracılığıyla toplam yutuculuk ve engel etkinliği parametreleri değerlendirilmiştir. Yansışım süresi 0.4 sn'dir. Çağrı merkezlerinde istenen yansışım süresi değer aralığındadır.

\section{Toplam Yutuculuğun ve Engel Etkinliğinin} Artırılması

Çalışma kapsamında personel sayısının azaltılması, uygun yerleşim modelinin konumlandırılması yolu ile gürültü düzeyinde azalma sağlanmış fakat gürültü kabul edilebilir değerlere indirilememiştir. En uygun model üzerinde (Model 5) toplam yutuculuğu arttrılarak, gürültü haritası tekrar oluşturulmuştur. Tablo 4 'te yer alan gereçlerin kullanımı ile oluşan gürültü haritası Şekil 12 'de yer almaktadır. Görüldüğü gibi, hacim genelinde gürültü düzeyi düşmüş, ancak yine kabul edilebilir değerler sağlanamamıştır.

Açık planlı ofislerde gürültü engeli olarak tasarlanabilecek ara bölme elemanlarının etkinliği, hacimde uygun akustik konforun sağlanması ve çalışma verimliliğinin artması açısından oldukça önemlidir. Toplam yutuculuğun artırılarak oluşturulan modelde engel etkinliği parametresi uygulanarak gürültü haritası hazırlanmıştır. Mevcut modelde $50 \mathrm{~cm}$ olan engel yüksekliği $70 \mathrm{~cm}$ 'e çıkarılarak simülasyon programı aracılığıyla engel etkinliği değerlendirilmiştir. Engel yüksekliği artrılarak oluşturulan gürültü haritası Şekil 12'deki gibidir. Çağrı merkezinde alıcı noktalarda hesaplanan gürültü düzeyi, kabul edilebilir değer olan 48 dBA'nın altındadır. Açık planlı ofisler için kabul edilebilir ses düzey aralığında olan bir tasarım modeli olarak oluşturulan Şekil

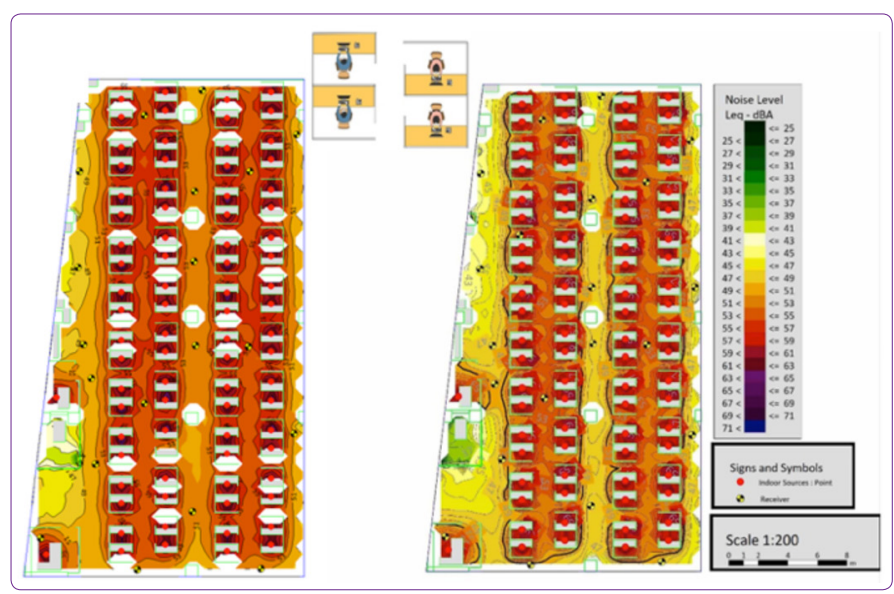

Şekil 12. Model 5-Toplam yutuculuğun artırılması (sol), Model 5-Toplam yutuculuğun ve engel etkinliğinin arttırılması (sağ).

Tablo 4. Açık planlı büro içerisinde toplam yutuculuğun artırılması için kullanılan malzemeler

Gereçler

\begin{tabular}{ll}
\hline & \\
Döşeme & Halı $20 \mathrm{~mm}$ öz keçe veya köpük üzerine \\
Tavan & Taş yünü asma tavan \\
Duvar & Akustik duvar astarı $50 \mathrm{~mm}$ \\
Duvar kaplama & Yutucu panel \\
Pencere & Lamine cam \\
Engel & Ahşap levha üzeri kumaş kaplama
\end{tabular}

\section{Ses yutma çarpanı (a)}

$125 \mathrm{~Hz}$

0.08

0.53

0.29

0.39

0.28

0.50

\begin{abstract}
$250 \mathrm{~Hz}$
\end{abstract}
0.24

0.95

0.67

0.96

0.20

0.75
$500 \mathrm{~Hz}$

0.57

0.97

0.67

0.96

0.110

0.90
$1 \mathrm{kHz}$

0.69

0.97

0.71

0.97

0.060

0.95
$2 \mathrm{kHz}$

0.71

0.97

0.77

0.97

0.030

0.90

$\mathbf{4 ~ k H z}$
0.73
0.98
0.97
0.98
0.020
0.80


12 'deki büro, çalışan sayısı, yerleşim modeli, yüzey gereçleri ve engel yüksekliği ile tasarımcının örnek alacağı bir model niteliğindedir.

\section{Sonuç}

Açık planlı ofis niteliğinde olan çağrı merkezlerinde, işitsel konforun sağlanmasında hacimdeki gürültünün, kabul edilebilir düzeyin altında kalmasının sağlanması, başta gelen belirleyicidir. Kabul edilebilir düzeyin sağlanmasında ise, hacmin mimari ve akustik tasarımı önem taşır. Bu çaışma ile açık planlı büro yapılarında akustik konfor koşulları incelenerek bu koşulları oluşturan parametreler örnek bir çağrı merkezi üzerinde değerlendirilmiştir. İncelemeye alınan çağrı merkezinde, personel sayısı, çalışma ünite tasarımı ve konumlandırılması, iç yüzey gereçlerinin ve engel panellerinin önemi ortaya konmuştur. Gerçekleştirilen çalışmalar değerlendirildiğinde;

- Açık planlı bürolarda kabul edilebilir gürültü düzeyinin sağlanmasında, çalışan kişi sayısı, çalışanların müşterilerle ve birbirleriyle iletişim halinde olması gürültü oluşumuna neden olduğu için daha özenli davranmaları gerektiği,

- Hacmin içerisinde, kullanıcıların birbirlerinin seslerinden olabildiğince az etkilenmelerini sağlayacak çalışma ünitesi tasarım düzenlerinin gerektiği,

- Çağrı merkezi içerisindeki yüzey gereçlerinin ve ses yutuculuklarının arttırımasının önemli olduğu,

- Bölme elemanı yüksekliğinin ve ses yutuculuk özelliklerinin, konuşma gizliliğinin sağlanması ve fon gürültüsünün azaltılması bakımından önemli olduğu belirlenmiştir.

Bu çalışma ile çağrı merkezlerinin fiziki konfor şartları değerlendirildiğinde şikâyetlerin genel olarak akustik koşulların yetersizliği ile ilişkili olduğu ortaya çıkmıştır. Akustik koşullar ve çağrı merkezi gürültüsünü azaltmak için önerilen önlemleri uygulayarak verimliliği artıran ve açık planlı ofisler için belirtilen gereksinimleri karşılayan bir çalışma ortamına ulaşmak mümkündür. Tasarım sürecinde hacim içerisinde doğru seçimlerin yapılmasının ve kullanılan gereçlerin sese ilişkin özelliklerinin bilinmesiyle, oluşturan hacimler işitsel konfor açısından daha nitelikli olacaktır.

\section{Teşekkür}

Bu çalışma, Yıldız Teknik Üniversitesi Bilimsel Araştırma Projeleri Koordinasyon Birimi'nce FDK-2018-3425 numaraIı proje ile desteklenen doktora tezinden üretilmiştir. Makalenin yazarları, YTÜ BAP Koordinasyon Birimi'ne teşekkür ederler.

\section{Kaynaklar}

Acustic Bulletin (2006) "Call Centre Room Acoustics", Ecophon https://www.acousticbulletin.com/call-centre-roomacoustics.

Brennan A., Mary S. (2002) "Traditional versus Open Office De־sign a Longitudinal Field Study", Environment and Behavior, 34(3), 279.

Brocolini L., Parizet E., Chevret P. (2016) “Effect of Masking Noise on Cognitive Performance and Annoyance in Open Plan Offi-ces", Applied Acoustics, 114, 44-55.

Çevre ve Şehircilik Bakanlığı (2018) "Binaların Gürültüye Karşı Korunması Hakkında Yönetmelikte Değişiklik Yapılmasına Dair Yönetmelik", Resmî Gazete Sayı: 30437, https://www. resmigazete.gov.tr/eskiler/2018/05/20180531-2.htm.

Haapakangas A., Kankkunen E., Hongisto V., Virjonen P., Oliva D., Keskinen E. (2011) "Effects of Five Speech Masking So-unds on Performance and Acoustic Satisfaction Implications for Open-Plan Offices", Acta Acustica United with Acustica, 97(4), 641-55.

Haapakangas A., Hongisto V., Hyönä J., Kokko J., Keränen J. (2014) "Effects of Unattended Speech on Performance and Subjective Distraction: The Role of Acoustic Design in OpenPlan Offices", Applied Acoustics, 86, 1-16.

Haka M., Haapakangas A., Keränen J., Hakala J., Keskinen E., Hongisto V. (2009) "Performance Effects and Subjective Dis-turbance of Speech in Acoustically Different Office Types - A Laboratory Experiment", Indoor Air, 19(6), 454-67.

Hongisto V. (2008) "Effects of sound masking on workers - a case study in a landscaped office", 9th International Congress on Noise as a Public Health Problem, 1-8, Foxwoords, CT.

Kaarlela-Tuomaala A., Helenius R., Keskinen E., Hongisto V. (2009) "Effects of Acoustic Environment on Work in Private Office Rooms and Open-Plan Offices - Longitudinal Study Du-ring Relocation", Ergonomics, 52(11), 1423-44.

Keränen J., \& Hongisto V. (2013) "Prediction of The Spatial Decay of Speech in Open-Plan Offices", Applied Acoustics, 74(12), 1315-25.

Maekawa Z., Lord, P. (1994) Environmental and Architectural Acoustics, E \& FN Spon, London, p.377.

Nilsson E., Hellström B. (2010) "Room Acoustic Design in OpenPlan Offices", 10ème Congrès Français d'Acoustique, 1-4, Lyon.

Passero C. R. M., Zannin P. H. T. (2012) “Acoustic Evaluation and Ad-justment of an Open-Plan Office through Architectural Design and Noise Control", Applied Ergonomics, 43, 1066-71.

Quentin P. (2002) The Architects' Handbook, Blackwell Science, Oxford.

TS ISO 1996-2 (2009) Çevre Gürültüsünün Tarifi, Ölçülmesi ve Değerlendirilmesi - Bölüm 2: Çevre Gürültü Seviyelerinin Ta-yini, Türk Standartları Enstitüsü, Ankara.

Zaglauer, M., Drotleff, H., Liebl, A. (2017) "Background Babble in Open-Plan Offices: A Natural Masker of Disruptive Speech", Applied Acoustics, 118, 1. 